\title{
Improved Hydrogen Embrittlement Resistance of Steel by Shot Peening and Subsequent Low-temperature Annealing
}

\author{
Makoto KAWAMORI, ${ }^{1) *}$ Wataru URUSHIHARA ${ }^{2)}$ and Satoshi YABU ${ }^{3)}$ \\ 1) Materials Research Laboratory, Technical Development Group, Kobe Steel, Ltd., 1-5-5 Takatsukadai, Nishi-ku, Kobe, Hyogo, \\ 651-2271 Japan. \\ 2) Research \& Development Planning Dept., Kobe Steel, Ltd., 1-5-5 Takatsukadai, Nishi-ku, Kobe, Hyogo, 651-2271 Japan. \\ 3) Material Solutions Division, Kobelco Research Institute, INC, 1-5-5 Takatsukadai, Nishi-ku, Kobe, Hyogo, 651-2271 Japan.
}

(Received on July 30, 2020; accepted on October 12, 2020; J-STAGE Advance published date:

December 20, 2020)

\begin{abstract}
The effect of shot peening and subsequent low-temperature annealing (SP treatment) on hydrogen embrittlement in tempered martensitic steel was investigated comparing the typical hydrogen charging methods, constant current controlled cathodic charging test and combined cyclic corrosion test (CCT). The hydrogen entry behavior was evaluated by hydrogen permeation technique and hydrogen visualization using secondary ion mass spectrometry. The SP treatment improved hydrogen embrittlement resistance in both hydrogen charging methods. On the other hand, the effect of SP treatment on the hydrogen entry was different depending on hydrogen charging method. The hydrogen entry was suppressed by SP treatment in the cathodic charging test because the compressive residual stress reduced hydrogen concentration in the surface layer and the potential increased by the increase of surface roughness and the formation of a surface film. In CCT, although the surface hydrogen concentration decreased due to compressive residual stress, the total hydrogen content did not decrease by SP treatment since the surface film disappeared by corrosion and an increase of surface roughness led to an increase in hydrogen entry sites. The improved hydrogen embrittlement resistance by the SP treatment in the cathodic charging test is a result of hydrogen entry suppression in addition to the effect of compressive residual stress. In CCT, the hydrogen embrittlement resistance was improved by SP treatment due to effect of compressive residual stress, i.e., the suppression of stress concentration as well as the stress-induced hydrogen diffusion in stress concentration area and the reduction of hydrogen concentration in the surface layer.
\end{abstract}

KEYWORDS: hydrogen embrittlement; hydrogen entry; hydrogen distribution; shot peening; lowtemperature annealing; tempered martensitic steel; hydrogen permeation technique; secondary ion mass spectrometry.

\section{Introduction}

Hydrogen embrittlement of high strength steel is caused by the accumulation of hydrogen entered from the environment in the stress concentration area. ${ }^{1,2}$ Thus, it is important to understand the hydrogen entry behavior to control the hydrogen embrittlement. ${ }^{3,4)}$ To improve the hydrogen embrittlement resistance, there has been much attempts from various viewpoints such as alloy design and surface treatment. Among them, shot peening (SP) introduces compressive residual stress to the surface layer of the workpiece, and is reported to be effective in improving abrasion resistance, fatigue strength, ${ }^{5-7)}$ and hydrogen embrittlement resistance. ${ }^{8-12)}$ As a mechanism of suppression of hydrogen embrittlement by SP, it has been proposed that compressive

\footnotetext{
* Corresponding author: E-mail: kawamori.makoto@kobelco.com
}

residual stress of steel surface reduces stress concentration, however, the effect of SP on the hydrogen entry into the steels ${ }^{11-14)}$ is not fully understood. Wilde et al. ${ }^{11)}$ and Li et al. ${ }^{12)}$ showed that hydrogen entry in the cathodic charging test was suppressed by SP. On the other hand, Tango et al. reported that the hydrogen entry in the immersion test of ammonium thiocyanate solution was promoted by SP. ${ }^{13)}$ Kubota et al. also reported that the initial concentration of diffusible hydrogen after the combined cycle corrosion test (CCT) was higher in steels with SP. ${ }^{14}$ ) As shown in the above reports, there is currently no unified view on the effect of SP on hydrogen entry. One of the reasons for this is that the hydrogen charging methods used in each study is different.

In the spring steels, the low-temperature annealing is often performed after SP in order to suppress the decline of sag resistance by SP. Particularly, in the case of automotive 
suspension coil spring steels, the temperature may rise in the coating process after SP. ${ }^{15)}$ However, the effect of SP followed by low-temperature annealing on hydrogen embrittlement and hydrogen entry into steel has not been sufficiently investigated. SP and subsequent low-temperature annealing (hereinafter referred to as SP treatment) changes various surface conditions such as plastic strain, surface roughness, surface film, and the introduction of compressive residual stress on the steel surface. It is necessary to investigate these factors separately to understand the effect of SP treatment of hydrogen embrittlement. In addition, since the change of the steel surface caused by SP treatment is a local region within several hundred $\mu \mathrm{m}$ from the surface layer, it is necessary to investigate the hydrogen distribution in the local surface region of $\mu \mathrm{m}$ order.

In the present work, the effect of SP followed by lowtemperature annealing on hydrogen embrittlement and hydrogen entry of high strength tempered martensitic steel was investigated. In order to understand the influence of SP treatment on hydrogen entry, the hydrogen entry behavior was examined by comparing the constant current controlled cathodic charging test and $\mathrm{CCT}$, which are the typical hydrogen charging methods. Furthermore, the hydrogen permeation technique was applied to clarify how various factors caused by SP treatment affect the hydrogen entry. Finally, the role of SP treatment on hydrogen embrittlement and hydrogen entry was discussed based on the results including the local hydrogen distribution evaluated by secondary ion mass spectrometry (SIMS).

\section{Experimental Procedure}

\subsection{Material}

The steel was prepared by vacuum induction furnace. Table 1 shows the chemical composition of the steel. The steel wires with a diameter of $12 \mathrm{~mm}$ were produced through hot forging and hot rolling. The steel was quenched at $930^{\circ} \mathrm{C}$ in a high-frequency induction heating furnace and tempered at $500^{\circ} \mathrm{C}$ to obtain a tempered martensitic struc-

Table 1. Chemical composition of steel (mass $\%$ ).

\begin{tabular}{cccccc}
\hline $\mathrm{C}$ & $\mathrm{Si}$ & $\mathrm{Mn}$ & $\mathrm{P}$ & $\mathrm{S}$ & $\mathrm{Cr}$ \\
\hline 0.61 & 1.48 & 0.74 & 0.009 & 0.009 & 0.71 \\
\hline
\end{tabular}
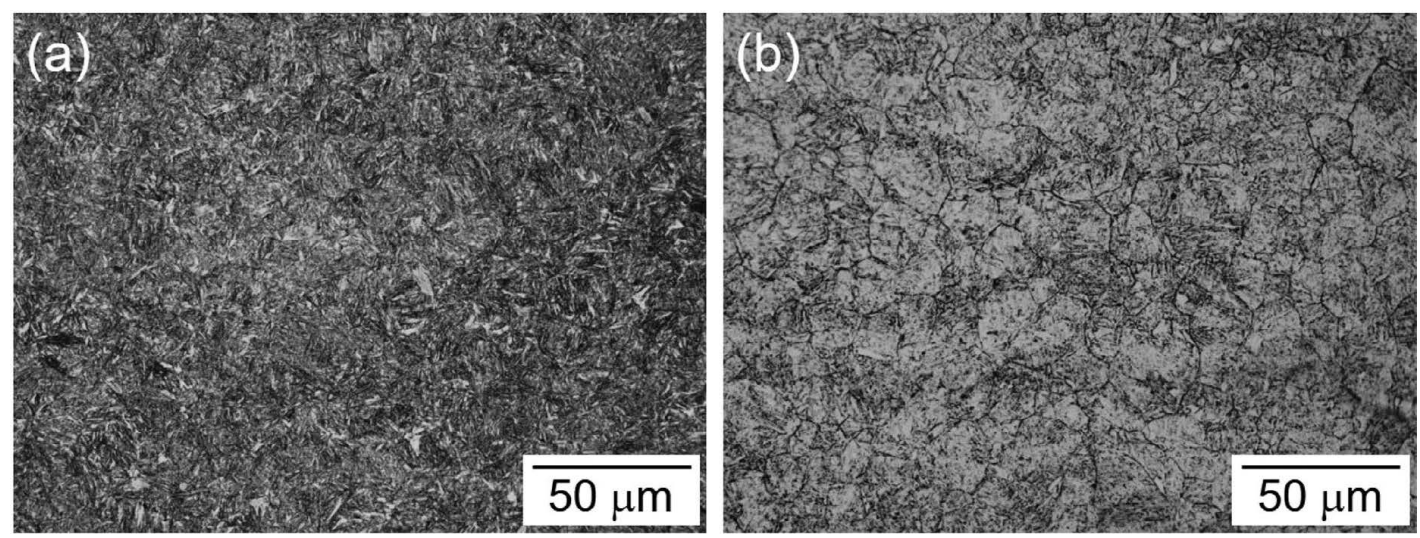

Fig. 1. Optical microscopy images of steel showing (a) lath martensite structure and (b) prior-austenite grain structure.

ture. Figure 1 shows the optical micrograph of martensitic structure and prior-austenite grain structure in this steel. The tensile test was conducted using a tensile test specimen cut from the center of the steel in the rolling direction. The tensile strength (TS) was confirmed to be $1965 \mathrm{MPa}$.

\subsection{SP Treatment}

SP was performed using the impeller-type SP machine. Steel balls with a diameter of $0.6 \mathrm{~mm}$ and a hardness of $60 \mathrm{HRC}$ were used. The peening speed was $60 \mathrm{~m} \mathrm{~s}^{-1}$ and a peening time was $300 \mathrm{~s}$. The low-temperature annealing after SP was carried out at $180^{\circ} \mathrm{C}$ for $2 \mathrm{~h}$. Here, the annealing temperature was determined within a range where the compressive residual stress introduced by SP did not disappear. The residual stress distribution introduced by SP followed by low-temperature annealing was measured by $\mathrm{X}$-ray residual stress measurement using the $\sin 2 \Phi$ method. The measurement direction was the longitudinal direction of the specimen. The depth distribution of the residual stress was obtained by electrolytic polishing. From the residual stress measurement results as shown in Fig. 2, the compressive residual stress was observed in the SP treated specimen up to a depth of about $300 \mu \mathrm{m}$ from the surface.

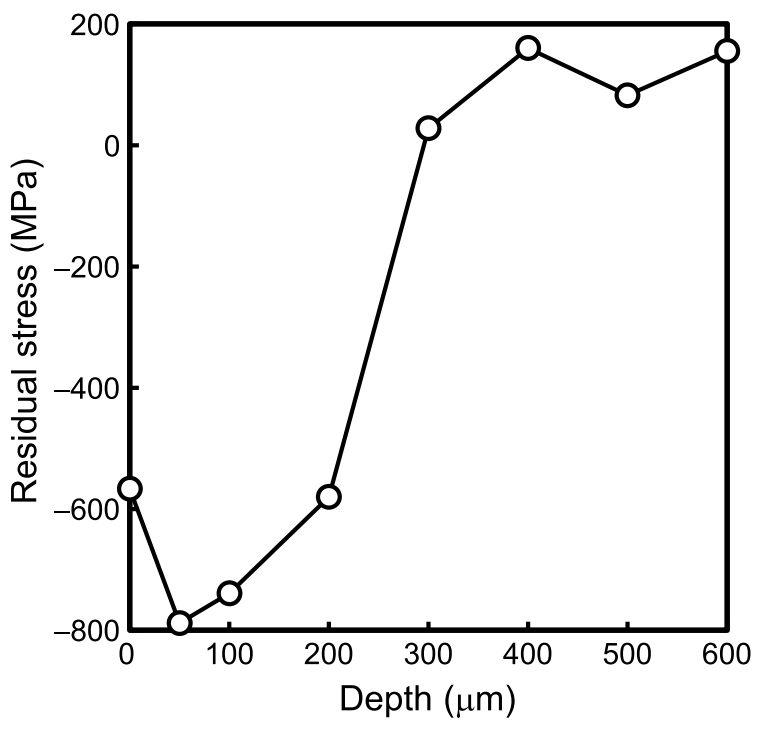

Fig. 2. Depth profile of residual stress of SP treated specimen. 


\subsection{Hydrogen Embrittlement Test}

\subsubsection{Cathodic Charging Test}

A tensile test specimen with a diameter of $4 \mathrm{~mm}$ and a gage length of $10 \mathrm{~mm}$ as shown in Fig. 3(a) was cut from the center of the steel in the rolling direction. For the specimen with SP treatment, the parallel portion was subjected to SP treatment as shown in Fig. 3(b). An artificial corrosion pit shown in Fig. 3(c) was produced into the center of the tensile test specimen by electric discharge machining. A potentiostat/galvanostat was used for the constant current controlled cathodic charging test. A platinum was used as the counter electrode, and $3 \% \mathrm{NaCl}+0.01 \mathrm{M} \mathrm{NH}_{4} \mathrm{SCN}$ aqueous solution and $1 \mathrm{M} \mathrm{NaOH}$ aqueous solution were used as the solutions. The cathodic charging test was performed at around $20^{\circ} \mathrm{C}$, and the cathodic current density was changed to $1-10 \mu \mathrm{A} \mathrm{mm}^{-2}$ to control the hydrogen content. The charging time was determined to $168 \mathrm{~h}$ based on the hydrogen diffusion calculation ${ }^{16)}$ result of the time that hydrogen can be saturated to the inside of the specimen with a diameter of $4 \mathrm{~mm}$ using the hydrogen diffusion coefficient $\left(0.7 \times 10^{-7} \mathrm{~cm}^{2} \mathrm{~s}^{-1}\right)$ which was evaluated by the hydrogen permeation technique. To prevent hydrogen escape, tensile test specimens were covered with zinc using electroplating. Thereafter, the slow strain rate tensile test (SSRT) was conducted at a rate of $2 \mu \mathrm{m} \mathrm{min}^{-1}$. The fracture surface was observed by scanning electron microscope (SEM) and non contact optical 3D measurement device. For the evaluation of hydrogen content, a specimen with the same shape (4 $\mathrm{mm}$ diameter, $10 \mathrm{~mm}$ length) as the parallel portion of the tensile test specimen was hydrogen-charged under the same conditions as in the SSRT test. The hydrogen content was evaluated by atmospheric pressure ionization mass spectrometer (API-MS). ${ }^{16)}$ The amount of diffusible hydrogen, which is considered to affect hydrogen embrittlement, was evaluated as an integrated value of hydrogen released when the temperature was raised from room temperature to $400^{\circ} \mathrm{C}$ at a heating rate of $12^{\circ} \mathrm{C} \mathrm{min}^{-1}$.

\subsubsection{Cyclic Corrosion Test}

A tensile test specimen with a diameter of $4 \mathrm{~mm}$ and a parallel length of $10 \mathrm{~mm}$ was cut from the central part of the steel, and the parallel portion was subjected to SP treat-

\section{(a) Tensile test specimen without SP treatment}

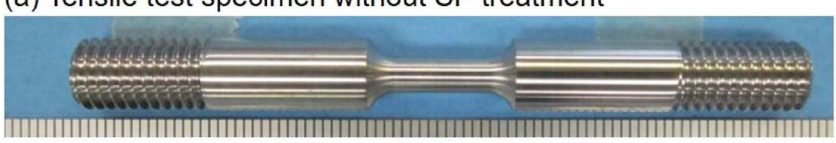

(b) Tensile test specimen with SP treatment

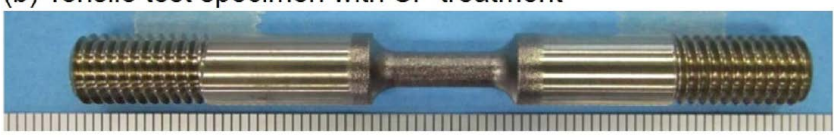

(c) Artificial pit

\begin{tabular}{|l|l|c|c|c|}
\hline Depth $\uparrow \longleftarrow$ Diameter & & Depth & Diameter \\
\cline { 2 - 4 } & Pit A & $100 \mu \mathrm{m}$ & $200 \mu \mathrm{m}$ \\
\hline & Pit B & $200 \mu \mathrm{m}$ & $400 \mu \mathrm{m}$ \\
\hline Pit C & $400 \mu \mathrm{m}$ & $800 \mu \mathrm{m}$ \\
\hline
\end{tabular}

Fig. 3. Photographic images of tensile test specimen (a) without and (b) with SP treatment. (c) Schematic illustration of artificial corrosion pit. (Online version in color.) ment. No artificial pits were introduced into the specimens for the purpose of evaluating corrosion pits formed in CCT. The specimens were hydrogen-charged by CCT which is composed of salt spray $\left(35^{\circ} \mathrm{C}, 5 \% \mathrm{NaCl}\right) 8 \mathrm{~h}$ and constant temperature and humidity $\left(35^{\circ} \mathrm{C}, \mathrm{RH} 60 \%\right) 16 \mathrm{~h}$. SSRT was conducted immediately after CCT at a rate of $2 \mu \mathrm{m} \mathrm{min}^{-1}$. For the evaluation of hydrogen content, a specimen with the same shape as the tensile test specimen was hydrogencharged under the same CCT conditions as in the SSRT test. The parallel portion of specimen was cut by a wet cutting machine. The rust, which is an inhibitor of hydrogen content measurement in the steel, ${ }^{17)}$ was removed by shot blast before hydrogen content measurement by API-MS.

\subsection{Hydrogen Permeation Technique}

A specimen with a width of $10 \mathrm{~mm}$, a length of $15 \mathrm{~mm}$, and a thickness of $0.5 \mathrm{~mm}$ was cut from the steel in the rolling direction. For the SP untreated specimen, the surface was wet-polished by an emery paper \#1500. The electropolishing of both surfaces was performed using a chromic acid-saturated phosphoric acid solution, and then Ni plating was conducted on one side of the specimen (hydrogen detection side) using a Watt bath. For the SP treated specimen, the SP treatment was previously conducted and a specimen was cut from the steel so that the hydrogen introduction side became the SP treated surface. The SP treated surface was not polished, and the other side (hydrogen detection side) was subjected to the electrolytic polishing and Ni plating. The specimen was sandwiched between two cells using a Devanathan-type double cell, ${ }^{18)}$ and the cell on the hydrogen detection side was filled with $1 \mathrm{M} \mathrm{NaOH}$ solution. Platinum and saturated calomel electrode (SCE) were used as a counter electrode and a reference electrode, respectively. The $\mathrm{Ni}$-electroplated side was polarized at $0.15 \mathrm{~V}$ vs. SCE. After confirming that the current density due to the passivation of $\mathrm{Ni}$ was sufficiently decreased, the cell on the hydrogen introduction side was filled with $1 \mathrm{M} \mathrm{NaOH}$. The hydrogen was charged at $20^{\circ} \mathrm{C}$ by constant current controlled cathodic charging test (1-10 $\left.\mu \mathrm{A} \mathrm{mm}^{-2}\right)$ using platinum as the counter electrode and potentiostat/galvanostat. Additionally, the potential of the hydrogen introduction side was measured during the test using a reference electrode of SCE. The hydrogen permeation current density $(J)$ was obtained from the current measured on the hydrogen detection side, and the hydrogen permeation coefficient $(J L)$ was calculated by multiplying the hydrogen permeation current density by the thickness of the specimen $(L)$.

\subsection{Visualization of Local Hydrogen Distribution by SIMS}

A specimen with a diameter of $4 \mathrm{~mm}$ and $10 \mathrm{~mm}$ in length were cut from the center of the steel. The SP treated specimen was subjected to the SP treatment on the circumferential side. The SP untreated and the SP treated specimens were deuterium-charged by constant current controlled cathodic charging test $\left(1 \mu \mathrm{A} \mathrm{mm}^{-2}\right)$ using a $3 \%$ $\mathrm{NaCl}+0.01 \mathrm{M} \mathrm{NH}_{4} \mathrm{SCN}$ solution with deuterium water as solvent. Here, deuterium (D) with low isotope abundance ratio was used instead of hydrogen $(\mathrm{H})$ as a tracer, because the background resulting from the naturally existing water $\left(\mathrm{H}_{2} \mathrm{O}\right)$ can be reduced. As a result, the evacuation time can 
be reduced, which enable to start the SIMS evaluation before the hydrogen desorb in the vacuum chamber. The deuterium-charged specimen was embedded in epoxy resin. The rolling-direction cross section $5 \mathrm{~mm}$ away from the edge was mirror-polished by wet-polishing. The observation points were the outer surface and center of the cross section of the specimen with a diameter $4 \mathrm{~mm}$. The negative deuterium ions $\left({ }^{2} \mathrm{D}^{-}\right)$were obtained in the scanning ion image mode under the primary ion beam conditions of $\mathrm{Cs}^{+}$and $15 \mathrm{keV}$.

\section{Results}

\subsection{Effect of SP Treatment on Hydrogen Entry}

Figure 4(a) shows the time dependence of the hydrogen content in the cathodic charging test using $3 \% \mathrm{NaCl}+0.01$ $\mathrm{M} \mathrm{NH} \mathrm{NCN}_{4}$ aqueous solution. The hydrogen content of SP treated specimen was about half that of the SP untreated specimen. When $1 \mathrm{M} \mathrm{NaOH}$ was used as the cathodic charging solution for the purpose of introducing a lower hydrogen content, the hydrogen content of the SP treated specimen was $0.5 \mathrm{ppm}$, which was about half that of the SP untreated specimen $(1.0 \mathrm{ppm})$. Therefore, it was confirmed that the hydrogen entry was suppressed by SP treatment in the cathodic charging test.

The time dependence of the hydrogen content during CCT is shown in Fig. 4(b). In CCT for $72 \mathrm{~h}$ (3 cycles) and $168 \mathrm{~h}$ (7 cycles), the hydrogen contents of the SP untreated and the SP treated specimens were almost the same. For 336 h (14 cycles), the hydrogen content of the SP treated specimen was slightly higher. In CCT, the effect of SP treatment on the suppression of hydrogen entry, which was observed in the cathodic charging test, was not observed. Namely, the effect of SP treatment on hydrogen entry was different depending on the hydrogen charging methods.

To investigate the details of the hydrogen entry behavior in the cathodic charging test, the hydrogen permeation test was conducted as shown in Fig. 5. The hydrogen was charged by constant current controlled cathodic charging (a) Cathodic charging test

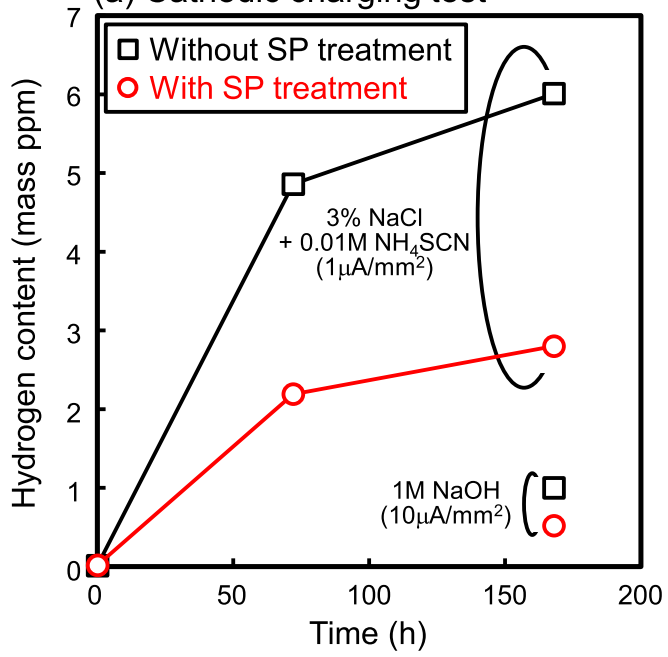

(b) CCT

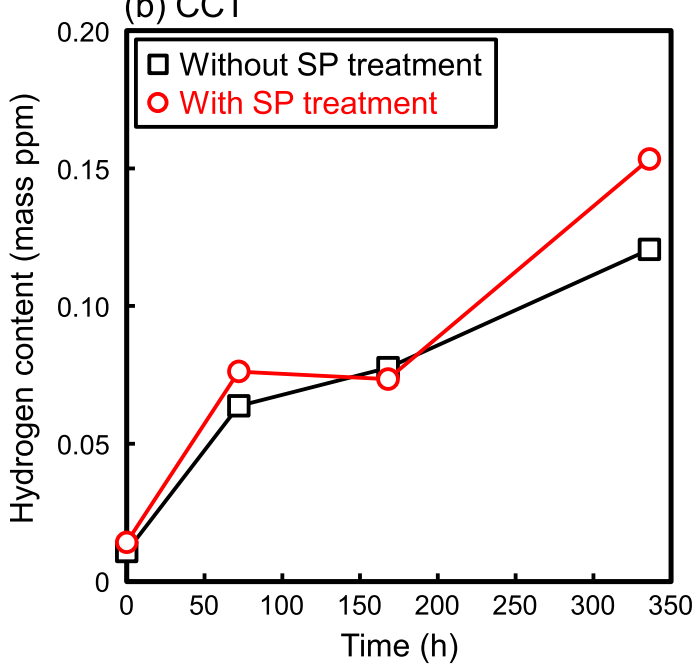

Fig. 4. Time dependence of hydrogen content in specimens charged by (a) cathodic charging test and (b) CCT. (Online version in color.)

(a) Hydrogen permeation coefficient

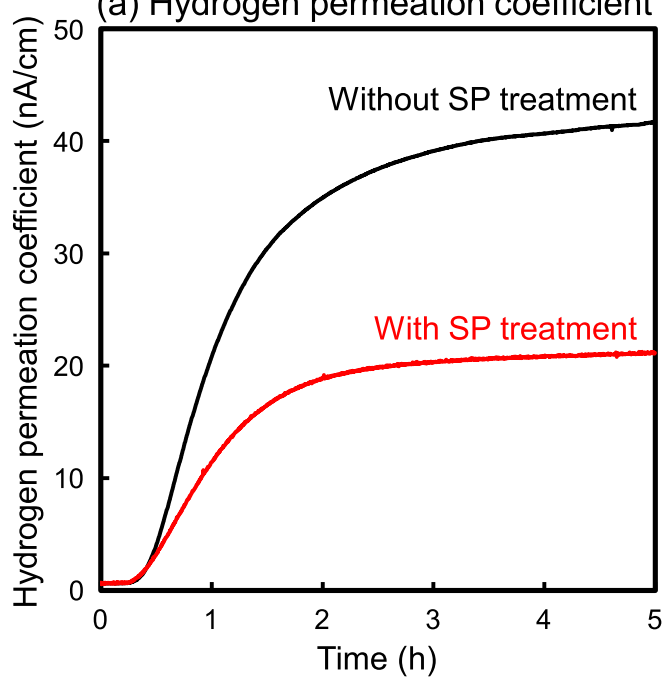

(b) Potential

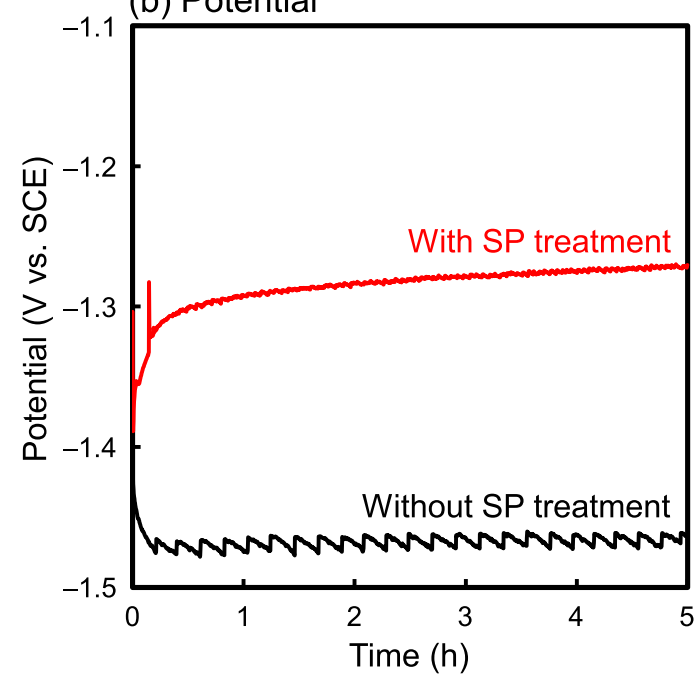

Fig. 5. Time dependence of (a) hydrogen permeation coefficient and (b) potential during the hydrogen permeation test by constant current controlled cathodic charging of $10 \mu \mathrm{A} \mathrm{mm} m^{-2}$ for specimens without and with SP treatment. (Online version in color.) 
test of $10 \mu \mathrm{A} \mathrm{mm}{ }^{-2}$. The hydrogen permeation coefficient $(J L)$ is an index of the magnitude of the surface hydrogen concentration $\left(C_{0}\right)$ on the hydrogen introduction side since the surface hydrogen concentration can be calculated from the hydrogen permeation coefficient using the following equation.

$$
C_{0}=\frac{J L}{D}
$$

The surface hydrogen concentration of SP untreated specimen evaluated by the hydrogen permeation test with hydrogen charging from one side was $0.8 \mathrm{ppm}$, which was relatively close to the hydrogen content of $1.0 \mathrm{ppm}$ when hydrogen was charged from the whole side at the same current density (Fig. 4(a)). Therefore, the hydrogen content in a relatively uniform SP untreated specimen is considered to be equivalent to the surface hydrogen concentration in the hydrogen permeation test. The hydrogen permeation coefficient of the SP treated specimen, which reached almost a steady value after $5 \mathrm{~h}$, was about half that of the SP untreated specimen (Fig. 5(a)). Thus, the suppression of hydrogen entry by SP treatment was also observed in the hydrogen permeation test. The apparent hydrogen diffusion coefficient $(D)$ was obtained by the half-rise time method expressed by the following equation ${ }^{19,20}$ )

$$
D=0.14 \frac{L^{2}}{t_{1 / 2}}
$$

where $L$ is the thickness of the specimen, and $t_{1 / 2}$ is the time for the hydrogen permeation current to reach half of the steady value. The hydrogen diffusion coefficients of the SP untreated specimen and the SP treated specimen were $0.7 \times$ $10^{-7}$ and $1.0 \times 10^{-7} \mathrm{~cm}^{2} \mathrm{~s}^{-1}$, respectively. The reduction of the hydrogen diffusion coefficient by the SP treatment was not observed.

The change in the potential on the cathodic charging side in the hydrogen permeation test is shown in Fig. 5(b). Compared with the SP untreated specimen, the potential of the SP treated specimen showed a noble value. In the case of the SP untreated specimen, the vibration of the potential was observed. The vibration is considered to be due to the change of the reaction area caused by the repeated desorption of hydrogen gas adsorbed on the surface into the solution. It has been reported that the lower the potential, the more easily hydrogen entries. ${ }^{21)}$ Thus, it was suggested that the difference in potential between SP treated and SP untreated specimens affected the hydrogen entry behavior. The mechanism of hydrogen entry suppression by SP treatment is described in detail in section 4 .

\subsection{Effect of SP Treatment on Hydrogen Distribution}

To examine the change of hydrogen trap state in the surface layer of the SP treated specimen, the local deuterium distribution was investigated by SIMS. As a prior confirmation of whether the change of hydrogen trap state could be evaluated by SIMS, the visualization of deuterium was conducted using the pre-strained tensile specimen. The $60^{\circ} \mathrm{V}$-shaped notched specimen (parallel part diameter: 4 $\mathrm{mm}$, notch diameter: $2.4 \mathrm{~mm}$, notch radius: $0.32 \mathrm{~mm}$ ) was prepared using SAE 9254 steel $(0.56 \% \mathrm{C}-1.44 \% \mathrm{Si}-0.68 \%$ $\mathrm{Mn}-0.008 \% \mathrm{P}-0.007 \% \mathrm{~S}-0.65 \% \mathrm{Cr}$ ) of $2000 \mathrm{MPa}$ tensile strength with a chemical composition close to that of the steel used in this study. The stress-displacement curves are shown in Fig. 6(a). After applying stresses of $90 \%$ and $80 \%$ to the notch tensile strength (3035 MPa), the specimens were unloaded. The specimens were deuterium-charged by constant current controlled cathodic charging test (1 $\mu \mathrm{A} \mathrm{mm}{ }^{-2}$ ) using a $3 \% \mathrm{NaCl}+0.01 \mathrm{M} \mathrm{NH}_{4} \mathrm{SCN}$ solution with deuterium water as solvent. After the specimens were embedded in epoxy resin, the sample preparation was performed to obtain deuterium ions $\left({ }^{2} \mathrm{D}^{-}\right)$images in the cross-section of the notch bottom, as shown in Fig. 6(b). The ${ }^{2} \mathrm{D}^{-}$intensity of the specimen subjected to the $90 \%$ of the fracture stress was higher than that of the specimen subjected to the $80 \%$ stress. The ${ }^{2} \mathrm{D}^{-}$intensity increased with an increase in the strain, indicating that the increase in the amount of defects (deuterium and/or hydrogen trap site) due to plastic deformation can be visualized by SIMS analysis using deuterium as a tracer.

Next, the ${ }^{2} \mathrm{D}^{-}$distributions in SP untreated and treated specimens were evaluated as shown in Fig. 7. Figures 7(a) and 7 (b) show the ${ }^{2} \mathrm{D}^{-}$distribution images and line profiles (a) Stress-displacement curves

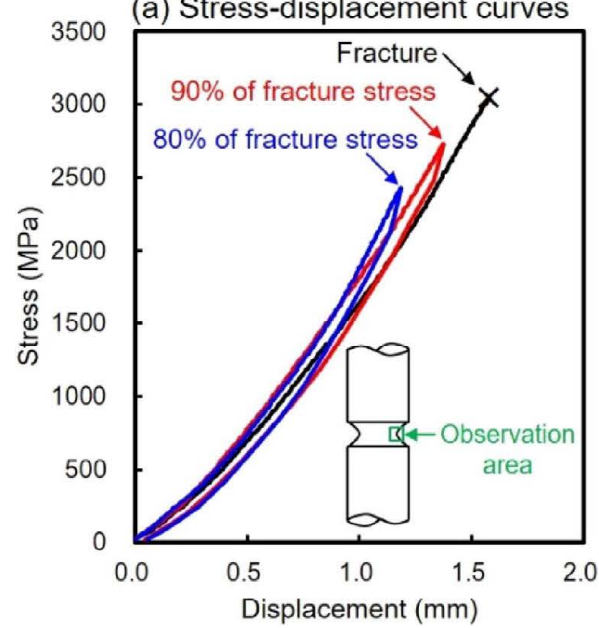

(b) ${ }^{2} \mathrm{D}$ distribution images

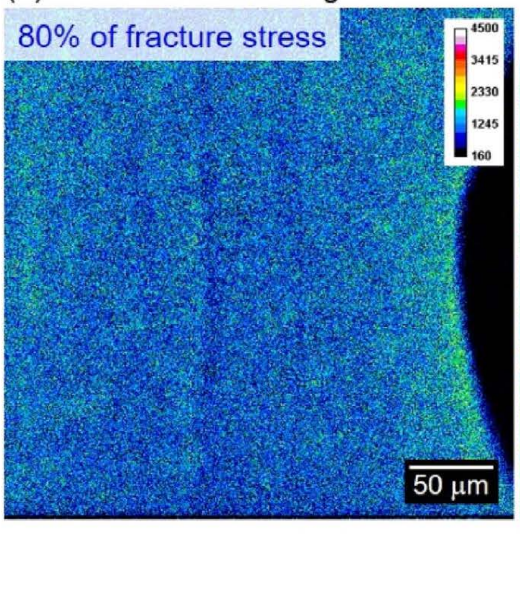

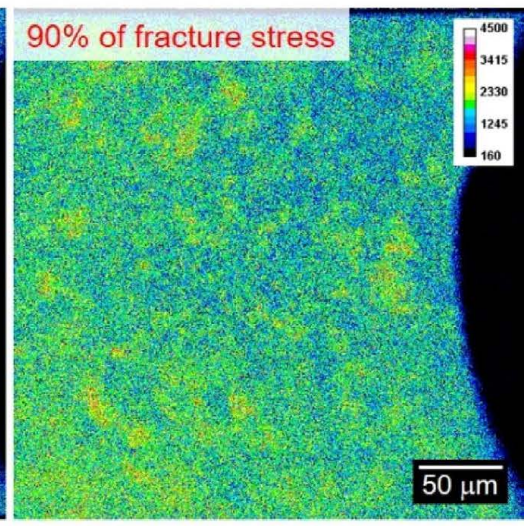

Fig. 6. (a) Stress-displacement curves of $60^{\circ} \mathrm{V}$-shaped notched specimens. (b) ${ }^{2} \mathrm{D}^{-}$distribution images in the crosssection of notch bottom of pre-strained specimens at $80 \%$ and $90 \%$ of fracture stress evaluated by SIMS. (Online version in color.) 
of ${ }^{2} \mathrm{D}^{-}$with a width of $50 \mu \mathrm{m}$ from top to bottom in ${ }^{2} \mathrm{D}^{-}$ distribution images, respectively. In the SP untreated specimen, ${ }^{2} \mathrm{D}^{-}$distributions in the surface layer and the center were similar, indicating that deuterium and/or hydrogen was relatively uniformly trapped. On the other hand, ${ }^{2} \mathrm{D}^{-}$ intensity in the surface layer of the SP treated specimen was lower than that in the center. The increase of the hydrogen trap site in the surface layer due to the plastic strain by SP was not confirmed. The ${ }^{2} \mathrm{D}^{-}$intensity of SP treated specimen in the surface layer increases from the outer surface to the center direction, which is considered to have some correlation with the residual stress profile as shown in Fig. 2. The SP and subsequent low-temperature annealing has the effect of reducing the hydrogen concentration of surface layer without increasing the hydrogen trap site.

\subsection{Effect of SP Treatment on Hydrogen Embrittle- ment}

Figure 8(a) shows the relationship between the hydrogen content and the maximum nominal stress of specimen with an artificial pit A (100 $\mu \mathrm{m}$ depth and $200 \mu \mathrm{m}$ in diameter $)$ in the SSRT test after $168 \mathrm{~h}$ of cathodic charging. The maximum stress decreased with an increase in hydrogen content in both the SP untreated and SP treated specimens. The reduction of the maximum stress with the increase of hydrogen content was more gradual in the SP treated specimen, indicating the hydrogen embrittlement resistance was improved by the SP treatment. The initiation site of fracture was not the artificial pit but the vicinity of the outer surface in the SP treated specimen, whereas it was all the artificial pit in the SP untreated specimen. That is, the artificial pit with a depth of $100 \mu \mathrm{m}$ was rendered harmless by the SP treatment. From the residual stress measurement (Fig. 2), the compressive residual stress exists in the SP treated specimen up to a depth of about $300 \mu \mathrm{m}$ from the surface, which contributes to the detoxification of the artificial pit with a depth of $100 \mu \mathrm{m}$. When either $1 \mathrm{M} \mathrm{NaOH}$ aqueous solution or $3 \% \mathrm{NaCl}+0.01 \mathrm{M} \mathrm{NH}_{4} \mathrm{SCN}$ aqueous solution was used as the cathodic charging solution, the hydrogen content was reduced to about half in the SP treated specimen. In the cathodic charging test, the hydrogen embrittlement resistance was improved by both effects of compressive residual stress and hydrogen entry suppression by SP treatment.

Figure 8(b) shows the relationship between the hydrogen content and the maximum nominal stress in SSRT after CCT. The maximum stress of both SP untreated and treated specimens decreased with increasing hydrogen content. The decrease in the maximum stress with the increase in hydrogen content was more gradual in the SP treatment specimen, indicating that the SP treatment improved the hydrogen embrittlement resistance. In the CCT, the suppression effect of hydrogen entry by SP treatment was not observed. It is considered that the maximum stress was improved mainly by compressive residual stress.

Figure 9 shows the results of the hydrogen embrittlement test conducted by changing the depth of the artificial pit in the cathodic charging test. Here, an aqueous solution of $3 \% \mathrm{NaCl}+0.01 \mathrm{M} \mathrm{NH}_{4} \mathrm{SCN}$ was used as the cathodic (a) ${ }^{2} D^{-}$distribution images Without SP treatment
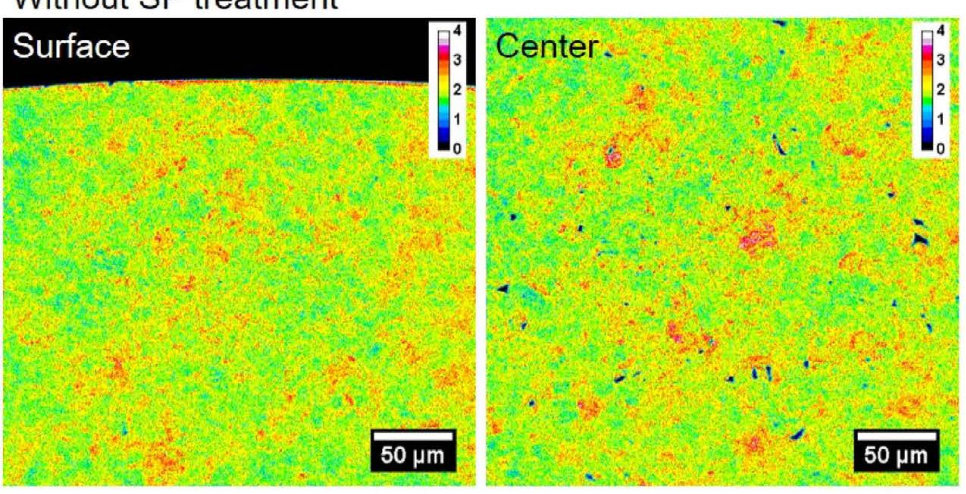

With SP treatment
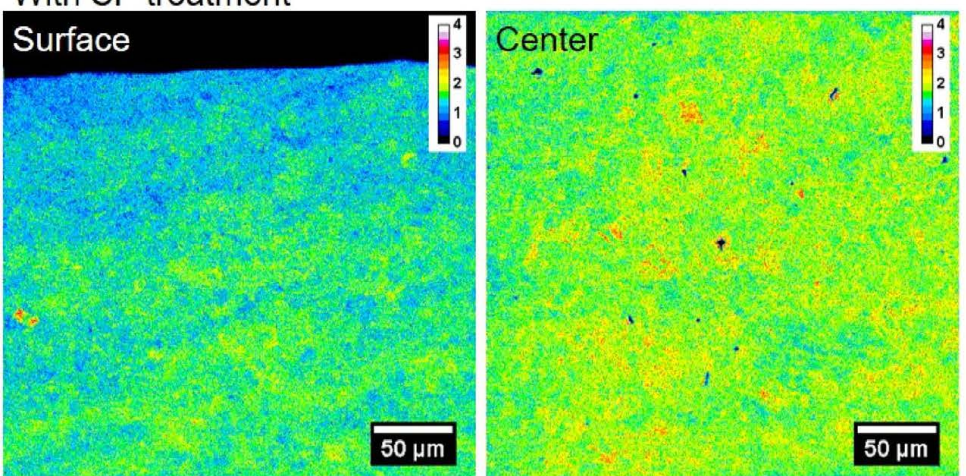

(b) Line profiles of ${ }^{2} \mathrm{D}^{-}$

Without SP treatment

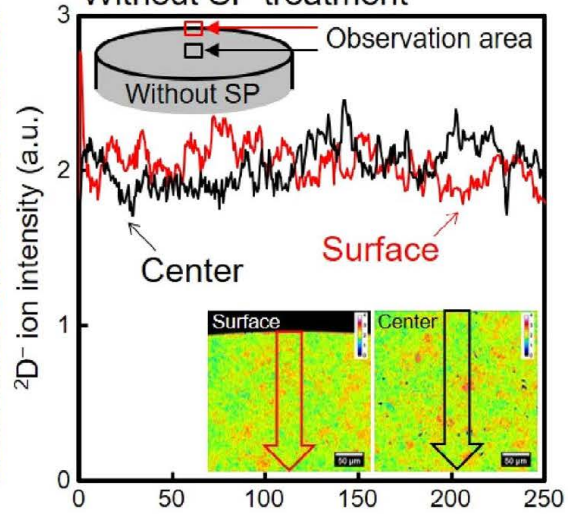

With SP treatment

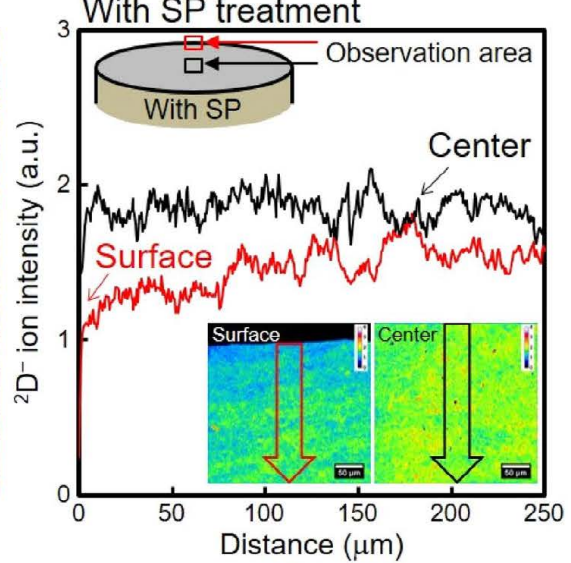

Fig. 7. (a) ${ }^{2} \mathrm{D}^{-}$distribution images at surface and center of specimens without and with SP treatment. (b) Line profiles of ${ }^{2} \mathrm{D}^{-}$with a width of $50 \mu \mathrm{m}$ from top to bottom in ${ }^{2} \mathrm{D}^{-}$distribution images. (Online version in color.) 
(a) Cathodic charging test

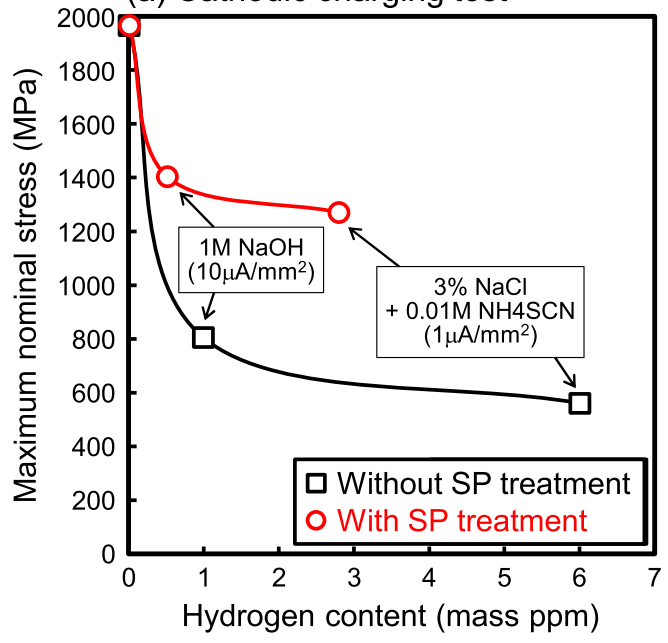

(b) $\mathrm{CCT}$

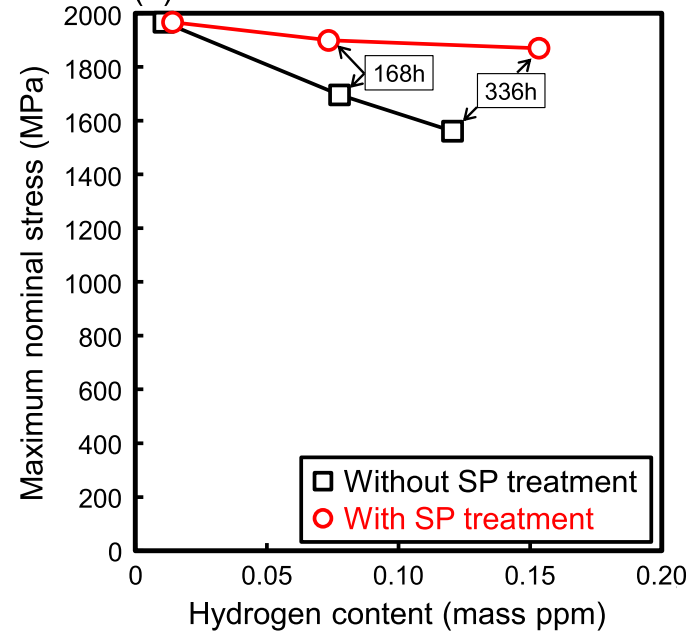

Fig. 8. Relationship between hydrogen content and maximum nominal stress evaluated by SSRT after (a) cathodic charging test and (b) CCT. (Online version in color.)

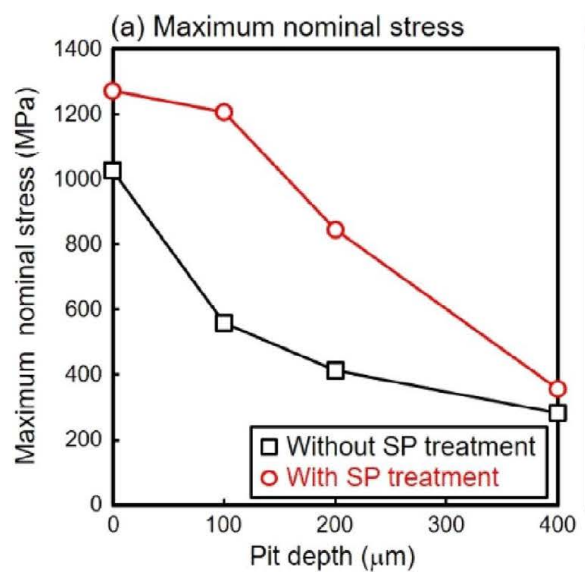

(b) Optical microscope images

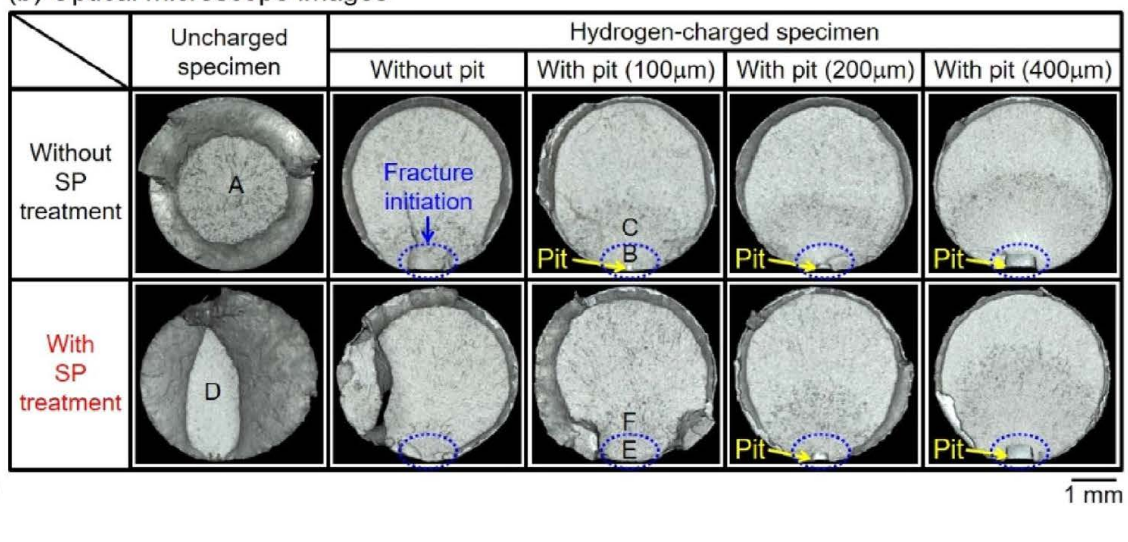

Fig. 9. (a) Relationship between artificial pit depth and maximum nominal stress of specimens without and with SP treatment evaluated by SSRT after cathodic charging test. (b) Optical microscope images of fracture surface after SSRT. (Online version in color.)

charging solution. The current density was $1 \mu \mathrm{A} / \mathrm{mm}^{2}$, and the charging time was $168 \mathrm{~h}$. From the artificial pit depth dependence of the maximum stress as shown in Fig. 9(a), the SP treated specimen showed higher maximum stress than the SP untreated specimen at all artificial pit depths. It was observed that the maximum stress of the untreated SP specimen significantly decreased when an artificial pit with a depth of $100 \mu \mathrm{m}$ was introduced compared with the case without artificial pit. As can be seen from the optical microscope images after the fracture shown in Fig. 9(b), the fracture initiation site of SP untreated specimen was near the surface in the absence of the artificial pit, and the fracture initiation site was changed to the pit by introducing the artificial pit with a depth of $100 \mu \mathrm{m}$. The sudden decrease in fracture stress was caused by the artificial pit which acted as the stress concentration site. On the other hand, in the SP treated specimen, there was almost no difference in the maximum stress with and without the artificial pit of $100 \mu \mathrm{m}$. As shown in Fig. 9(b), even when an artificial pit with a depth of $100 \mu \mathrm{m}$ was introduced into the SP treated specimen, the fracture started from the vicinity of the surface which was not an artificial pit. When the depth of the artificial pit was made deeper to $200 \mu \mathrm{m}$ and $400 \mu \mathrm{m}$, the fracture initiation site of SP treated specimen became the artificial pit, and the maximum stress significantly decreased. This is because the artificial pit was formed at a position deeper than the region where the compressive residual stress was sufficiently applied and they acted as a stress concentration site.

Figure 10 shows the SEM images of the regions A-F on the fracture surface after the hydrogen embrittlement test shown in Fig. 9(b). The fracture surfaces of uncharged specimens were dimple regardless SP treatment (Figs. 10(A), 10(D)). On the other hand, in the SP untreated specimen with hydrogen charging, quasi cleavage (QC) fracture surface was observed near the pit that was the initiation site of fracture (Fig. 10(B)), and the intergranular (IG) fracture surface was observed slightly inside the pit (Fig. 10(C)). In the SP treated specimen, the QC fracture surface was observed both near the outer surface (Fig. 10(E)), which is the fracture initiation site, and slightly inside the outer surface (Fig. 10(F)). It has been reported that the area fraction of the IG fracture increased with increasing diffusible hydrogen content. ${ }^{22}$ ) The hydrogen content of SP treated specimen was lower than that of SP untreated specimen. The suppression of hydrogen entry by SP treatment may affect the reduction of IG fracture surface. 


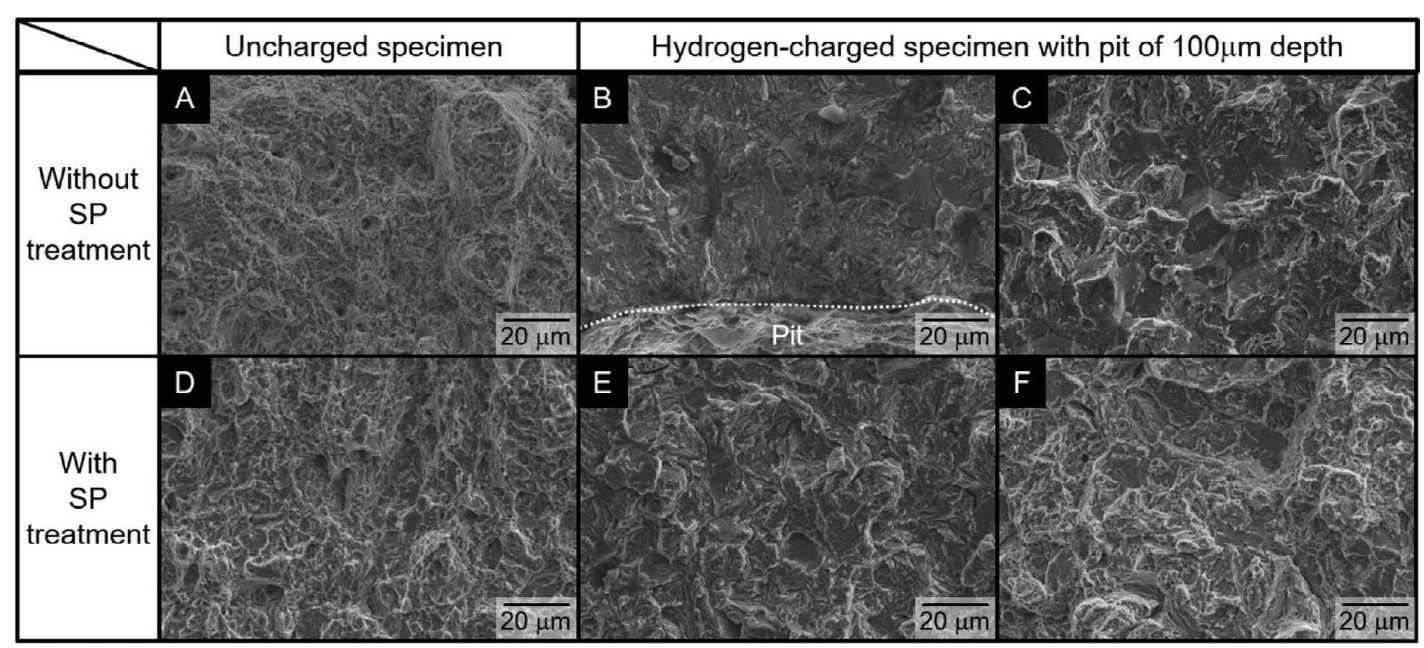

Fig. 10. SEM images of fracture surface of (A) to (F) in Fig. 9(b).

\section{Discussion}

The hydrogen embrittlement resistance is improved by SP treatment in both the cathodic charging test and CCT. On the other hand, the effect of SP treatment on hydrogen entry was different depending on the hydrogen charging method, but the mechanism is not clear. As the mechanism of the hydrogen entry suppression effect by SP in the cathodic charging test, Li et al. proposed (i) the decrease in the hydrogen diffusion rate due to the introduction of hydrogen trap sites (dislocation, etc.) accompanying plastic deformation, (ii) the decrease in hydrogen entry due to compressive residual stress, and (iii) the decrease in the cathodic charging current density due to an increase in surface roughness. ${ }^{12)}$ In this study, the low-temperature annealing was performed after SP and the SP treated specimen shows a light yellow to brown temper color accompanied by the formation of the oxide film as shown in Fig. 3(b). Thus, in addition to the changes in the surface conditions described above, (iv) the effect of surface film was also considered. Here, the hydrogen permeation technique was applied to clarify the mechanism of the different effect of SP treatment on hydrogen entry in hydrogen charging methods. Additionally, the effect of SP treatment on the hydrogen embrittlement was discussed based on the hydrogen distribution evaluated by SIMS.

\subsection{Effect of Plastic Strain}

As described in the section 3.1, the decrease in hydrogen diffusion coefficient due to SP treatment was not observed. Therefore, the suppression of hydrogen entry cannot be explained by (i) the decrease in hydrogen diffusion rate due to the introduction of trap sites accompanying plastic deformation. However, it is generally known that the hydrogen trap sites such as dislocation and vacancy are introduced by plastic deformation such as cold working ${ }^{23)}$ and the hydrogen diffusion coefficient decreases. ${ }^{24)}$ Similarly, SP is a kind of cold working, and it has been reported that the hydrogen diffusion coefficient decreases with SP. ${ }^{12)}$ Brass et al. demonstrated that the hydrogen was trapped in the cold worked layer introduced by the SP using tritium autoradiography. ${ }^{25)}$ However, in this research, the increase of hydrogen trap site was not observed in the surface layer of SP treated specimen as shown in Fig. 7(b). The reason for this is considered to be the effect of low-temperature annealing after SP. Suzuki and Tuchida et al. reported that the newly formed hydrogen trap site in tempered martensitic steel due to plastic strain disappeared by aging treatment at $200^{\circ} \mathrm{C}$ for $1 \mathrm{~h}^{26)}$ This phenomenon was explained by the stabilization of the dislocation through Cottrell interaction with carbon and the loss of the ability to trap hydrogen. ${ }^{27)}$ Nagumo et al. reported that the hydrogen trapping sites of low-carbon steel increased by plastic deformation decreased by annealing at $200^{\circ} \mathrm{C}$ because the vacancy-type defects formed by plastic deformation disappeared by subsequent annealing. ${ }^{28)}$ Similarly, in the SP treated specimen in this study, the hydrogen trap site increased by SP partly disappeared by the subsequent low-temperature annealing, so that the hydrogen enrichment in the surface layer and the decrease of hydrogen diffusion coefficient were not observed. Though the low-temperature annealing after SP has been conventionally carried out for improving sag resistance, from the point of view of hydrogen embrittlement, it may be an effective method for decreasing the hydrogen trap sites formed by plastic strain due to SP.

\subsection{Effect of Compressive Residual Stress}

As shown in Fig. $7,{ }^{2} \mathrm{D}^{-}$intensity in the surface layer of the SP treated specimen was detected lower than that in the center, indicating hydrogen content of surface layer becomes lower by SP treatment. The hydrogen concentration changes due to hydrostatic stress, which can be estimated by the following equation $22,29,30$ )

$$
H^{*}=H \exp \left(\frac{\sigma_{m} \Delta V}{R T}\right)
$$

where $H^{*}$ is the hydrogen content considering the influence of hydrostatic stress, $H$ is the hydrogen content when stress is not applied, $\sigma_{\mathrm{m}}$ is the hydrostatic stress regarding the tensile stress as positive, $\Delta V$ is the molar volume of hydrogen in iron $\left(2 \times 10^{-6} \mathrm{~m}^{3} / \mathrm{mol}\right),{ }^{31)} R$ is the gas constant, and $T$ is the temperature. Figure 11(a) shows the distribution of $H^{*}$ calculated in the surface of SP treated specimen by assuming the hydrostatic stress as the residual stress profile as shown in Fig. 2. $H$ and $T$ were assumed to be $1 \mathrm{ppm}$ and room temperature $(298 \mathrm{~K})$. Figure 11(b) shows the 
distributions of ${ }^{2} \mathrm{D}^{-}$ion intensity normalized based on the results of Fig. 7(b) at center and surface of the SP treated specimen by assuming the average of ${ }^{2} \mathrm{D}^{-}$ion intensity at center as 1 . The calculated $H^{*}$ profile has some correlation with profile of the normalized ${ }^{2} \mathrm{D}^{-}$ion intensity. The calculated $H^{*}$ and normalized ${ }^{2} \mathrm{D}^{-}$ion intensity was close to 0.6 near the outer surface. They increase toward the center and reach approximately 0.8 at $250 \mu \mathrm{m}$ from the outer surface. Bockris et al. reported that the lowering of hydrogen solubility produced by the application of compressive stresses suggests a possibility of reducing or eliminating hydrogen embrittlement. ${ }^{32)}$ In this study, we demonstrated for the first time that hydrogen concentration was reduced by compressive residual stress due to SP treatment by hydrogen visualization using SIMS and it was effective in suppressing hydrogen embrittlement.

In order to investigate the effect of (ii) compressive residual stress on hydrogen entry by eliminating the influence of (iii) surface roughness increase and (iv) surface film, the hydrogen permeation test was conducted by using the SP treated specimen whose surface of $50 \mu \mathrm{m}$ was polished. Figure 12 shows the photographs of the SP untreated specimen (Fig. 12(a)), SP treated specimen (Fig. 12(b)), and SP treated specimen whose surface of $50 \mu \mathrm{m}$ was polished (Fig. 12(c)). Since compressive residual stress existed from the surface layer to about $300 \mu \mathrm{m}$ in the SP treated specimen, it is considered that compressive residual stress remains to some extent even if it is reduced by polishing. The hydrogen permeation test was carried out by changing the cathodic current densities. Figure 13 shows the relationship between the cathodic current density and the hydrogen permeation coefficient which became a steady value after $5 \mathrm{~h}$. The hydrogen diffusion coefficient of the SP untreated and the SP treated specimens were almost the same, which agrees with the reports of Wilde et al. ${ }^{11)}$ and Bockris et al. ${ }^{32)}$ that the compressive stress does not affect the hydrogen diffusion coefficient. The hydrogen permeation coefficient of the SP treated specimen with removal of surface (Fig. 13(c)) was not significantly reduced compared to that of the SP untreated specimen (Fig. 13(a)). Thus, the compressive residual stress introduced by SP treatment reduces the surface hydrogen concentration, however, the half reduction of hydrogen content by the SP treatment as shown in Fig. 4(a) (and the difference between Figs. 13(a) and 13(b)) cannot be explained by the compressive residual stress alone because the ratio of the region where the compressive residual stress exists to the whole specimen is as small as approximately $30 \%$ at the maximum.

\subsection{Effect of Surface Roughness}

To investigate the effect of (iii) surface roughness by eliminating the influence of the (iv) surface film, the hydro-
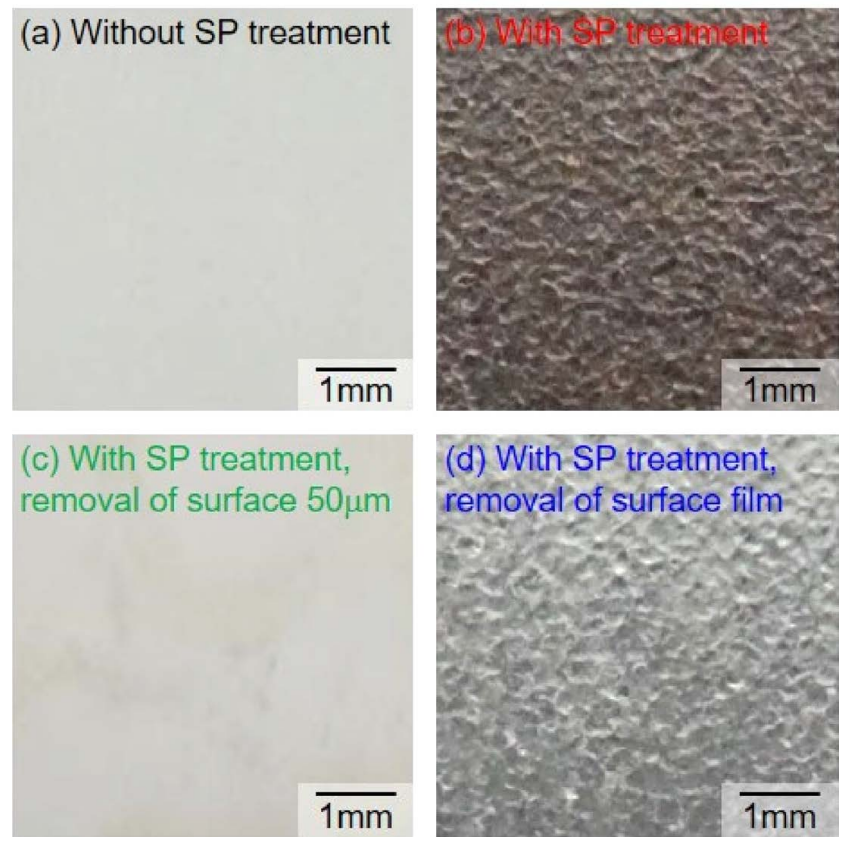

Fig. 12. Photographic images of (a) SP untreated specimen, (b) SP treated specimen, (c) SP treated specimen with removal of surface $50 \mu \mathrm{m}$, and (d) SP treated specimen with removal of surface film. (Online version in color.) (a) Calculated hydrogen content

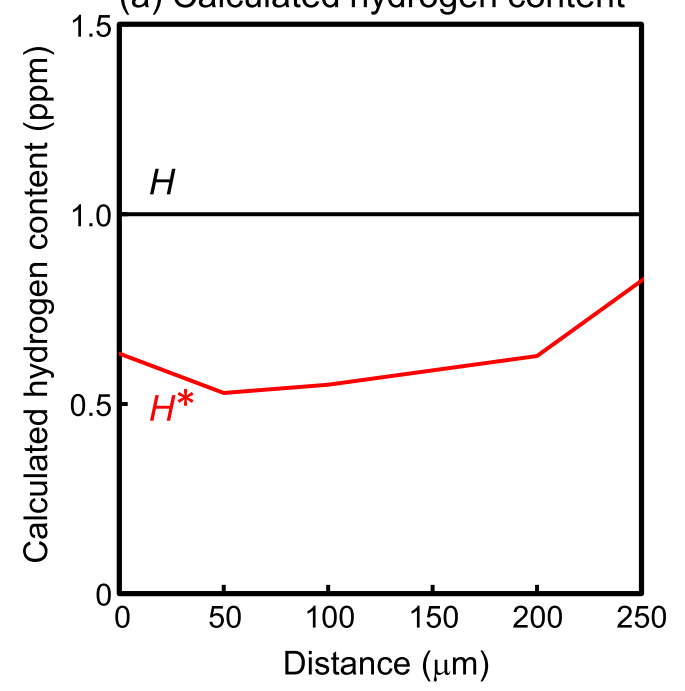

(b) Line profiles of normalized ${ }^{2} \mathrm{D}^{-}$

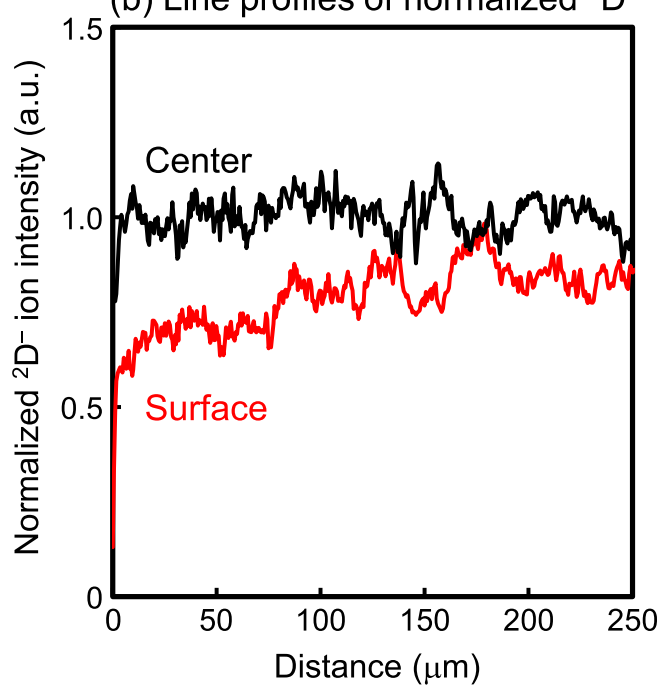

Fig. 11. (a) Distribution of calculated hydrogen content without stress $(H)$ and hydrogen content considering the residual stress $\left(H^{*}\right)$ in the surface of SP treated specimen. (b) Line profiles of ${ }^{2} \mathrm{D}^{-}$ion intensity normalized based on the results of Fig. 7(b) at center and surface of the SP treated specimen. (Online version in color.) 


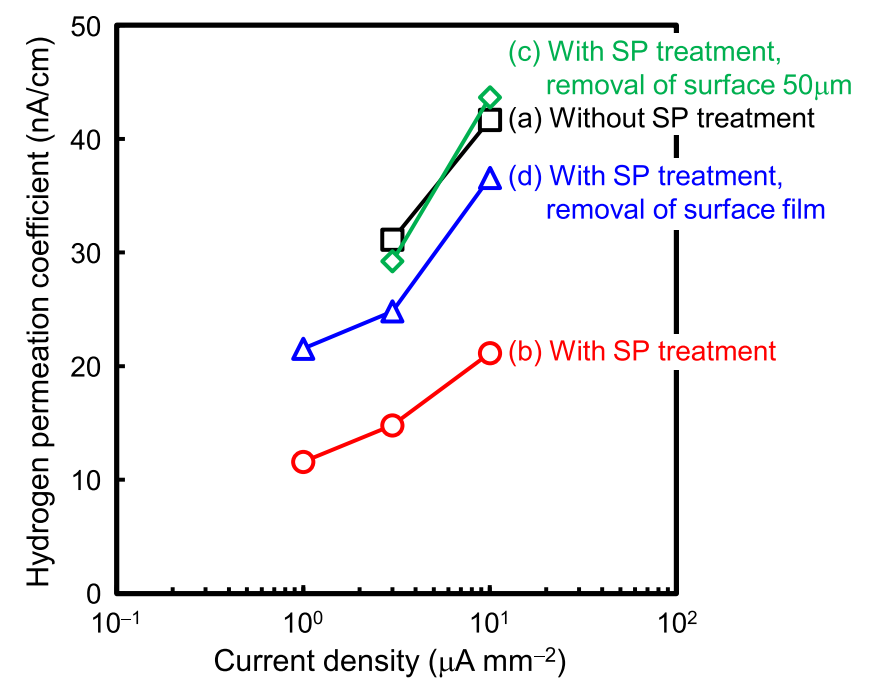

Fig. 13. Relationship between cathodic current density and hydrogen permeation coefficient in the hydrogen permeation test of (a) SP untreated specimen, (b) SP treated specimen, (c) SP treated specimen with removal of surface $50 \mu \mathrm{m}$, and (d) SP treated specimen with removal of surface film. (Online version in color.)

gen permeation test was conducted by using SP treated specimen whose surface film was removed by brief electropolishing so that the surface roughness did not change. The appearance photograph and the hydrogen permeation coefficient are shown in Figs. 12(d) and 13(d), respectively. The hydrogen permeation coefficient of the SP treated specimen with removal of the surface film decreased compared to that of the SP untreated specimen. The decrease is due to the surface roughness, considering that the change of plastic strain and the compressive residual stress in the surface layer caused by the SP treatment do not greatly reduce the hydrogen permeation coefficient. In this study, the cathodic charging test was performed using the surface area assumed to be flat surface. As can be seen from the appearance of Fig. 12(b), the surface of the SP treated specimen is so rough that the current density decreases and the amount of hydrogen entry decreases.

\subsection{Effect of Surface Film}

The hydrogen permeation coefficient of the SP treated specimen (Fig. 13(b)) was lower than that of the SP treated specimen with removal of the surface film (Fig. 13(d)). This indicates that the surface film affected the suppression of hydrogen entry. In order to understand the hydrogen entry suppression mechanism by SP treatment, the potential on the cathodic charging side was measured in the hydrogen permeation test as shown in Fig. 14. No change was observed in the polarization behavior of the SP untreated specimen (Fig. 14(a)) and the SP treated specimen with removal of surface $50 \mu \mathrm{m}$ (Fig. 14(c)). This indicates that the compressive residual stress applied by SP treatment does not affect the hydrogen generation reaction. The polarization curve of the SP treated specimen with removal of surface film (Fig. 14(d)) shifts to a noble side as compared with the SP untreated material (Fig. 14(a)) due to an increase in surface roughness. Compared with the SP treated specimen with removal of surface film (Fig. 14(d)), the polarization

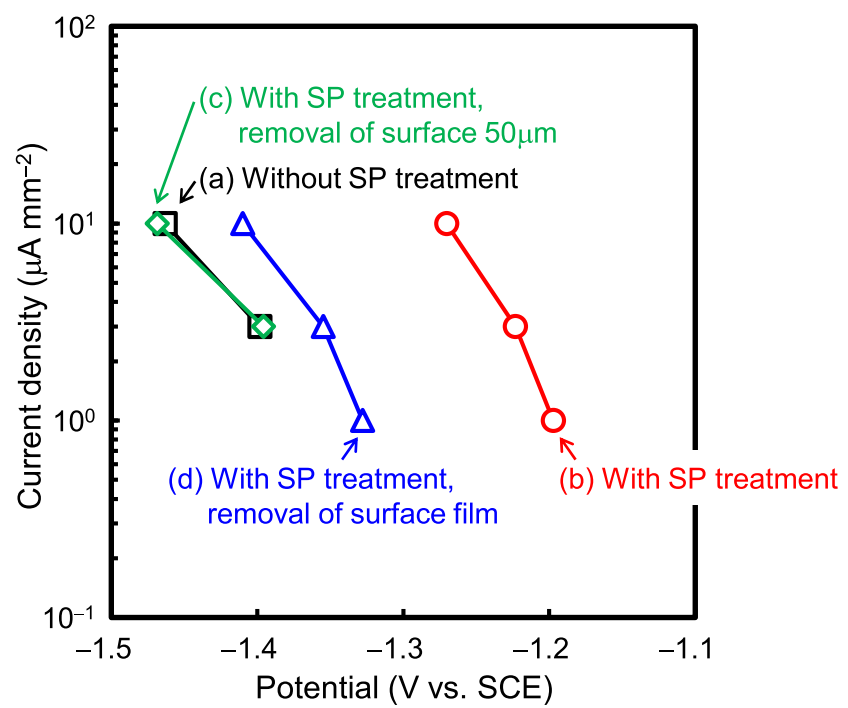

Fig. 14. Relationship between potential and current density during the hydrogen permeation test of (a) SP untreated specimen, (b) SP treated specimen, (c) SP treated specimen with removal of surface $50 \mu \mathrm{m}$, and (d) SP treated specimen with removal of surface film. (Online version in color.)

curve of the SP treated specimen (Fig. 14(b)) shifts to a noble side, suggesting that the surface film affected the polarization behavior. The surface film is considered to be the ferric oxide formed during the low-temperature annealing after SP. It is estimated that the polarization curves shift to a noble side because the reduction current density increases by the reduction reaction of the ferric oxide film and/or the change in catalytic activity of the hydrogen generation reaction.

\subsection{Comparison of Cathodic Charging Test with CCT on Hydrogen Entry and Hydrogen Embrittlement}

Figure 15 shows the relationship between the potential and the hydrogen permeation coefficient in the hydrogen permeation test with varying the cathodic current densities. As the potential becomes more noble, the hydrogen permeation coefficient decreases. The suppression of hydrogen entry by SP treatment in the cathodic charging test can be explained by the change in potential. Namely, the increase in surface roughness and the formation of the surface film by the SP treatment make the potential more noble than that of the SP untreated specimen due to the change of polarization behavior as shown in Fig. 14. Additionally, the compressive residual stress reduces the hydrogen content of the surface. These factors result in the suppression of the hydrogen entry in the cathodic charging test. The improved hydrogen embrittlement resistance by the SP treatment in the cathodic charging test is a result of hydrogen entry suppression in addition to the reduction of stress concentration by the compressive residual stress.

In the case of CCT, it is considered that the surface hydrogen concentration decreases due to the compressive residual stress as well as in the cathodic charging test. However, the surface film disappeared early because of the corrosion, and the increase in surface roughness resulted in the increase of the hydrogen entry sites. Thus, the effect of suppressing hydrogen entry by the surface roughness and 


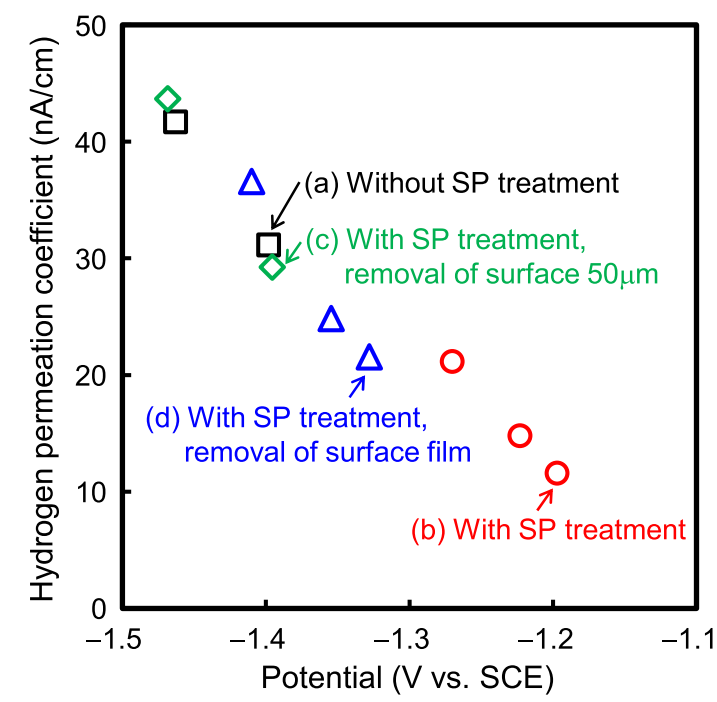

Fig. 15. Relationship between potential and hydrogen permeation coefficient during the hydrogen permeation test of (a) SP untreated specimen, (b) SP treated specimen, (c) SP treated specimen with removal of surface $50 \mu \mathrm{m}$, and (d) SP treated specimen with removal of surface film. (Online version in color.)

the surface film as observed in the cathodic charging test did not appear. As a result, the total amount of hydrogen did not decreased with SP treatment. The improvement of hydrogen embrittlement resistance by SP treatment in CCT is mainly because the compressive residual stress lowers the hydrogen concentration in the surface layer, and further reduces the stress concentration and stress-induced hydrogen diffusion in stress concentration area such as pits.

\section{Conclusions}

In this study, the effect of SP followed by low-temperature annealing (SP treatment) on the hydrogen embrittlement and hydrogen entry was investigated using both constant current controlled cathodic charging test and CCT. The following conclusions have been obtained.

(1) The hydrogen embrittlement resistance was improved by the SP treatment in both hydrogen charging methods. However, the effect of the SP treatment on the hydrogen entry was different depending on the hydrogen charging methods. The hydrogen content decreased by SP treatment in the cathodic charging test, and the reduction of hydrogen content was not observed in CCT.

(2) The suppression of hydrogen entry by SP treatment in the cathodic charging test can be explained by the compressive residual stress which contributes to the reduction of hydrogen concentration in the surface layer and an increase in potential due to the increased surface roughness and the formation of surface film. The formation of hydrogen trap site by SP treatment was not observed in the surface layer, which is assumed to be due to the disappearance of the hydrogen trap site by low-temperature annealing after SP. The improvement of hydrogen embrittlement resistance by the SP treatment in the cathodic charging test is a result of hydrogen entry suppression in addition to the effect of compressive residual stress.

(3) In CCT, the surface film disappeared due to corrosion, and the increase in surface area led to an increase in hydrogen entry sites. Therefore, although the surface hydrogen content decreased by the compressive residual stress, the total hydrogen content did not decrease by SP treatment. The improvement of hydrogen embrittlement resistance by SP treatment in CCT is mainly due to the effect of compressive residual stress, i.e., the suppression of stress concentration as well as the stress-induced hydrogen diffusion in stress concentration area such as pits and the reduction of hydrogen concentration in the surface layer.

\section{REFERENCES}

1) S. Matsuyama: Delayed Fracture, The Nikkan Kogyo Shimbun, Tokyo, (1989), 123.

2) S. Matsuyama: Tetsu-to-Hagané, 80 (1994), 679 (in Japanese).

3) E. Akiyama: ISIJ Int., 52 (2012), 307.

4) T. Omura, T. Kushida, F. Nakasato, S. Watanabe and I. Oyamada: Tetsu-to-Hagané, 91 (2005), 478 (in Japanese).

5) Y. Murakami, M. Kobayashi, T. Makino, T. Toriyama, Y. Kurihara, S. Takasaki and R. Ebara: Trans. Jpn. Soc. Mech. Eng. A, 57 (1991), 2305.

6) K. Takahashi, T. Amano, T. Miyamoto, K. Ando, F. Takahashi, A. Tange, H. Okada and Y. Ono: Trans. Jpn. Soc. Spring Eng., 52 (2007), 9.

7) K. Takahashi, T. Hayashi, K. Ando and F. Takahashi: Trans. Jpn. Soc. Spring Eng., 55 (2010), 25.

8) B. E. Wilde and T. Shimada: Scr. Metall., 22 (1988), 551.

9) Y. Watanabe, N. Hasegawa and M. Inoue: J. Soc. Mater. Sci., Jpn., 41 (1992), 933.

10) M. Kubota, T. Suzuki, D. Hirakami and K. Ushioda: ISIJ Int., 55 (2015), 2667.

11) B. E. Wilde and I. Chattoraj: Scr. Metall. Mater., 26 (1992), 627.

12) X. Li, J. Zhang, Y. Wang, M. Ma, S. Shen and X. Song: Mater. Des., 110 (2016), 602

13) K. Tango, M. Sugiyama, T. Suzuki and M. Ayada: Trans. Jpn. Soc. Spring Eng., 48 (2003), 15.

14) M. Kubota, D. Hirakami and K. Ushioda: Trans. Jpn. Soc. Spring Eng., 58 (2013), 1.

15) Suspension Spring Working Group, Research Committee on Durability of High-Strength Steel Wire: Trans. Jpn. Soc. Spring Eng., 39 (1994), 101.

16) T. Iwata: Koberunikusu, 26 (2017), No. 47, 17.

17) Y. Ishiguro, S. Ootsuka, D. Mizuno and K. Fujimura: ISIJ Int., 55 (2015), 2677.

18) M. A. V. Devanathan and Z. Stachurski: J. Electrochem. Soc., 111 (1964), 619.

19) T. Tsuru: Zairyo-to-Kankyo, 63 (2014), 3 (in Japanese).

20) J. McBreen, L. Nanis and W. Beck: J. Electrochem. Soc., 113 (1966), 1218.

21) J. O’M. Bockris, J. McBreen and L. Nanis: J. Electrochem. Soc., 112 (1965), 1025.

22) M. Wang, E. Akiyama and K. Tsuzaki: Corros. Sci., 49 (2007), 4081

23) K. Takai, H. Shoda, H. Suzuki and M. Nagumo: Acta Mater., 56 (2008), 5158.

24) P. C. Rivera, V. P. Ramunni and P. Bruzzoni: Corros. Sci., 54 (2012), 106.

25) A. M. Brass, J. Chêne, G. Anteri, J. Ovejero-Garcia and L. Castex: J. Mater. Sci., 26 (1991), 4517.

26) N. Suzuki, N. Ishii and Y. Tuchida: Tetsu-to-Hagané, 80 (1994), 855 (in Japanese).

27) Y. Tsuchida: J. High Press. Inst. Jpn., 57 (2019), 191.

28) M. Nagumo, K. Ohta and H. Saitoh: Scr. Meter., 40 (1999), 313.

29) J. C. M. Li, R. A. Oriani and L. S. Darken: Z. Phys. Chem., 49 (1966), 271.

30) A. Nozue: Okurehakai-Kaimei-no-Shintenkai (Advances in Delayed Fracture Solution), ISIJ, Tokyo, (1997), 197 (in Japanese).

31) H. Wagenblast and H. A. Wriedt: Metall. Trans., 2 (1971), 1393.

32) J. O’M. Bockris, W. Beck, M. A. Genshaw, P. K. Subramanyan and F. S. Williams: Acta Metall., 19 (1971), 1209. 